\title{
Correlation between Serum Ferritin Levels and Liver Stiffness measured by Fibroscan in patients with Chronic Hepatitis C
}

\author{
Saba Latif ${ }^{1}$, Quratulain Kalam², Bader Faiyaz Zuberi ${ }^{3}$
}

\begin{abstract}
Objective: To determine correlation between transient elastography values with serum ferritin and duration of infection in patients of hepatitis $C$.

Methods: A cross-sectional study was conducted at medical units of Civil Hospital, Karachi. The study protocol was approved by the Research Evaluation Unit of College of Physician and Surgeon Pakistan (CPSP). Patients fulfilling inclusion criteria were included after taking informed consent. Serum ferritin levels were tested by standard laboratory procedures and transient elastography by fibroscan. Regression analysis was done to see correlation of ferritin with transient elastography and duration of HCV.

Results: Over all 120 patients fulfilling the selection criteria were selected after informed consent. These included $68(56.7 \%)$ male \& $52(43.3 \%)$ female. Significant differences in ferritin levels by Fibrosis stages were observed by ANOVA ( $d f=3 ; F=12.768 ; p=<0.001)$. Serum ferritin showed linear pattern across Fibrosis stages $(F=33.948 ; p=<0.001)$. Regression analysis of ferritin and duration of HCV showed significant impact on TE scores $\left(r^{2}=0.317\right)$.

Conclusions: There is significant correlation between serum ferritin and duration of HCV with TE scores.
\end{abstract}

KEYWORDS: Chronic hepatitis C, Ferritin, Fibroscan, Transient elastography.

doi: https://doi.org/10.12669/pjms.36.3.1288

How to cite this:

Latif S, Kalam Q Zuberi BF. Correlation between Serum Ferritin Levels and Liver Stiffness measured by Fibroscan in patients with Chronic Hepatitis C. Pak J Med Sci. 2020;36(3):355-359. doi: https://doi.org/10.12669/pjms.36.3.1288

This is an Open Access article distributed under the terms of the Creative Commons Attribution License (http://creativecommons.org/licenses/by/3.0), which permits unrestricted use, distribution, and reproduction in any medium, provided the original work is properly cited.

\section{INTRODUCTION}

Chronic hepatitis $\mathrm{C}(\mathrm{CHC})$ is a major infectious disease which is mainly cause of morbidity worldwide in patients with liver disease, and liver trans-

1. Dr. Saba Latif, MBBS, FCPS. Senior Registrar,

2. Dr. Quratulain Kalam, MBBS, FCPS.

Senior Registrar,

3. Dr. Bader Faiyaz Zuberi, MBBS, FCPS.

Professor of Medicine,

Dow University of Health Sciences,

Karachi, Pakistan.

1,2: Patel Hospital, Karachi, Pakistan.

Correspondence:

Dr. Bader Faiyaz Zuberi

C-404, Al-Habib Pride,

CL-8/5, Civil Lines,

Karachi, Pakistan.

E-mail: bader@zuberi.net

* Received for Publication:

* Accepted for Publication:
June 27, 2019

January 2, 2020 plantation. ${ }^{1}$ Around $2.35 \%$ of world population, i.e., approximately 160 million people are suffering with HCV. ${ }^{2}$ Although, its prevalence in most of the countries is 1 to $2 \%$, but Pakistan has a high prevalence rate of $4.7 \% .^{3}$ In the last two to three decades, Chronic Hepatitis C (CHC) which progress to cirrhosis is reported in $20 \%$ of the cases; out of which $25 \%$ cases developed liver disease, hepatocellular carcinoma and such cases needed liver transplantation. ${ }^{4}$ Liver biopsy is the gold standard for determining the degree of liver fibrosis, but carries potentially life threatening complications. Fibroscan being a noninvasive method uses ultrasonic waves for determining liver stiffness and estimating the degree of liver fibrosis. ${ }^{5}$ According to a meta-analysis study, specificity and sensitivity of fibroscan in chronic patients of $\mathrm{HCV}$ for diagnoses of cirrhosis was estimated as $83.0 \%$ and $91.0 \%$, respectively. ${ }^{5}$

Hyper-ferritinemia in $\mathrm{CHC}$ may reflect ongoing necroinflammatory events, and it often accompanies 
with iron deposits in hepatic mesenchymal cells. ${ }^{6}$ Raised ferritin levels play an important role of intervening the process which is associated with hepatic injury. ${ }^{7}$ A study demonstrates that in serum ferritin levels, the longitudinal changes are highly correlated with values of Transient Elastography (TE) acquired through fibroscan $(\mathrm{r}=0.836, p<0.001) .{ }^{8}$ In patients who acquired the infection of $\mathrm{HCV}$ due to blood transfusion, the risk for cirrhosis is estimated as double. ${ }^{9}$ Another study results showed that fibroscan has encouragement by biochemical activity variations of liver disease in liver stiffness and CHC, and when AST is at low levels, it can underestimate the fibrosis. Therefore, it is necessary to adjust the age and AST during getting Fibroscan result so that significant accuracy could be determined..$^{10}$ Screening with non-invasive strategies can detect the disease at early stage and intervention could be initiated. ${ }^{11,12}$

This study was conducted to determine the correlation of TE scores with duration of $\mathrm{CHC}$ and serum ferritin levels. This study will greatly benefit patients with hyper-ferritinemia in which presence of liver involvement would be documented. It will also help patients of $\mathrm{CHC}$ in determination of their liver status and thus help in better planning of their management.

\section{METHODS}

A descriptive cross sectional study was carried out in all five medical units of Civil Hospital, Karachi, during $1^{\text {st }}$ June 2016 to $30^{\text {th }}$ November 2016. Approval of synopsis was taken from CPSP. Informed consent from the patients was taken. Patients of either sex suffering with chronic hepatitis $\mathrm{C}$ disease for more than six months were selected through non-probability consecutive sampling. Patients with other viral hepatitis infections, hepatic cancer, history of alcohol consumption $>25 \mathrm{~g} /$ day and patients with ascites detected by Ultrasound abdomen were excluded. The selected patients were tested for serum ferritin level by standard laboratory procedures and TE scores by fibroscan. Ten measurements of fibroscan were taken, and mean value was taken for analysis. All the procedure was done under supervision of consultant having experience of five years and above.

TE values from Fibroscan were assigned to fibrosis stages as under:

$\begin{array}{lll}2.0-7.9 \mathrm{kPa} & = & \mathrm{F} 0-\mathrm{F} 1 \\ 8.0-9.9 \mathrm{kPa} & = & \mathrm{F} 2 \\ 10.0-13.9 \mathrm{kPa} & = & \mathrm{F} 3 \\ \geq 14.0 & = & \mathrm{F} 4\end{array}$

A sample size of 112 achieves $90 \%$ power to detect a difference of -0.3 between the null hypothesis correlation of 0.0 and the alternative hypothesis correlation of 0.3 using a two-sided hypothesis test with a significance level of 0.05 . Sample size calculation was done using PASS 2019 software.

Data was collected through a predesigned proforma. The collected data was analyzed through SPSS version 22.0. For quantitative variables like age, disease duration, TE scores \& ferritin, mean \pm SD was determined, and were tested with gender by Student's T-test. Frequency and percentages were calculated for gender and fibrosis stage and were tested by $\chi^{2}$ test. Ferritin values were tested for significance with Fibrosis score by ANOVA, test for linear model and Post-Hoc analysis were also done. Followed by regression analysis of serum ferritin with Fibrosis Score and $\mathrm{r}^{2}$ values were calculated. Significance was set at $\leq 0.05$.

\section{RESULTS}

Over all 120 patients fulfilling the selection criteria were selected after informed consent. From which 68 (56.7\%) were male \& 52 (43.3\%) were female. Mean age of the patient was 45.8 \pm 14.2 years, mean hepatitis $C$ duration was 3.8 \pm 1.2 years, mean TE value was $10.0 \pm 3.3 \mathrm{kPa}$ \& mean Serum Ferritin was 85.2. \pm 35.2 . No significant difference was observed in age when analyzed for gender $(p=0.07)$, while duration of HCV was found significantly increased in females $(p=0.041)$, TE values were significantly increases in females $(p=0.015)$ and serum ferritin was significantly low in females $(p=0.037)$. Details of T-Test are given in Table-I.

Table-I: Distribution of Age, Duration of Hepatitis C, TE Value \& Serum Ferritin Student's T-Test.

\begin{tabular}{lcccccc}
\hline & Male $n=68$ & Female $n=52$ & Total $n=120$ & $p$ value & \multicolumn{2}{c}{ 95\% Confidence Interval } \\
\cline { 2 - 6 } & Mean $\pm S D$ & Mean $\pm S D$ & Mean $\pm S D$ & & Lower & Upper \\
\hline Age (years) & $43.5 \pm 7.5$ & $48.6 \pm 19.6$ & $45.8 \pm 14.2$ & 0.070 & -11.001 & 0.442 \\
Duration of HCV (years) & $3.6 \pm 1.5$ & $4.0 \pm 0.7$ & $3.8 \pm 1.2$ & 0.041 & -0.806 & -0.017 \\
TE value (kPa) & $9.4 \pm 3.2$ & $10.8 \pm 3.2$ & $10.0 \pm 3.3$ & 0.015 & -2.623 & -0.281 \\
Serum Ferritin & $91.1 \pm 37.4$ & $77.5 \pm 31.1$ & $85.2 \pm 35.3$ & 0.037 & 0.859 & 26.249 \\
\hline
\end{tabular}




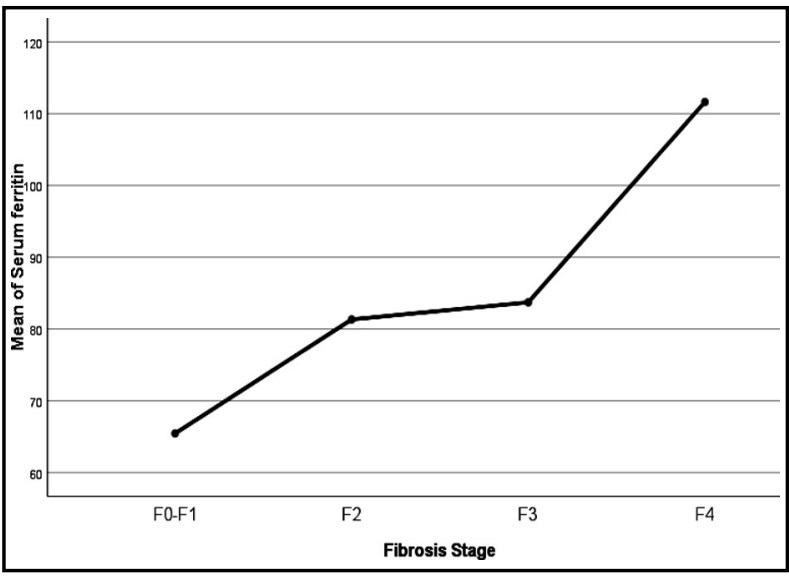

Fig.1: ANOVA Post-Hoc Means Plot of Serum Ferritin on Fibrosis Stage.

Serum Ferritin levels were analyzed by Fibrosis Scores by One-Way ANOVA test. Test showed significant differences in ferritin levels by Fibrosis stages ( $\mathrm{df}=3 ; \mathrm{F}=12.768 ; p=<0.001$ ). Serum ferritin showed linear pattern across Fibrosis stages $(\mathrm{F}=33.948 ; p=<0.001)$. This effect is shown graphically in Fig.1. Post Hoc multiple comparisons showed significant increase in serum ferritin from F0-F1 to F2, non-significant increase from $\mathrm{F} 2$ to $\mathrm{F} 3$ \& significant increase from F3 to F4. Details in Table-II.

Regression analysis was done to see the impact of Serum Ferritin and duration of HCV (Independent Variables) on Fibrosis Score (Dependent Variable). Results showed $\mathrm{r}^{2}=0.317$ showing significant impact of the independent variables on dependent variable (Table-III). Normal P-P Plot of Regression Standardized Residual is given in Fig.2. Significance level of Serum Ferritin was $p$ $<0.001$ and that of Duration of HCV was $p=0.004$

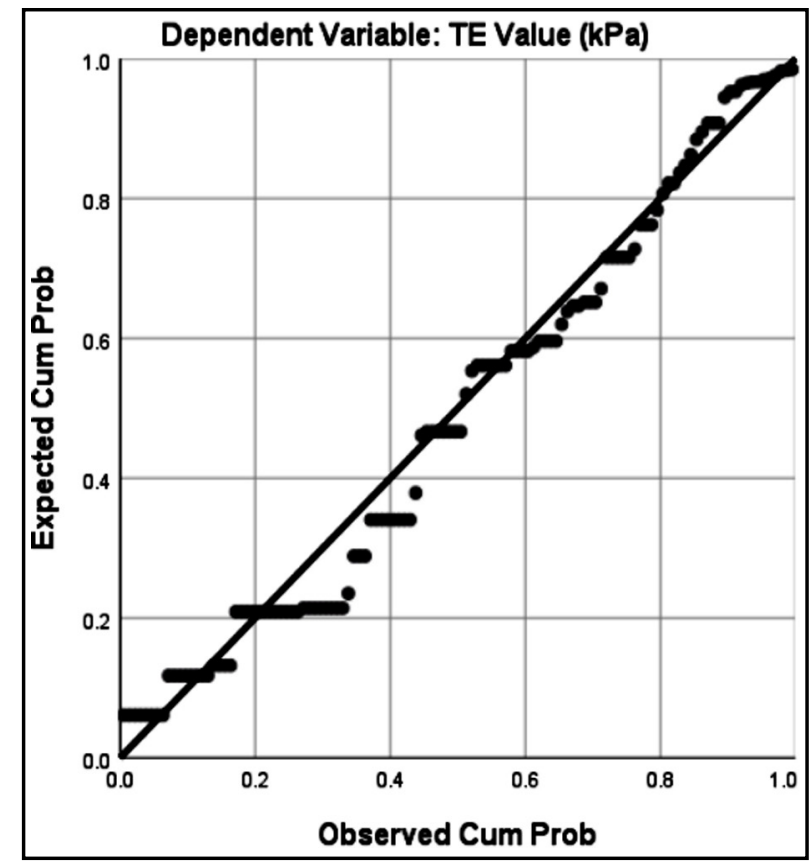

Fig.2: Normal P-P Plot of Regression Standardized Residual.

(Table-IV). Thus both Serum Ferritin and Duration of HCV have significant impact on Fibrosis Score in $\mathrm{HCV}$.

\section{DISCUSSION}

TE is fast replacing invasive tests for assessment of liver fibrosis not only in adults but in pediatric population as well. ${ }^{13}$ Its accuracy has been well established now with several studies on this subject and to rule out significant fibrosis without invasive tests like liver biopsy. ${ }^{14,15}$ Our study showed significant correlation with cause/effect analysis of regression that duration

Table-II: ANOVA Post Hoc multiple comparisons by Games-Howell Method.

\begin{tabular}{cccccc}
\hline (I) Fibrosis Stage & (J) Fibrosis Stage & Mean Difference (I-J) & $p$ value & \multicolumn{2}{c}{ 95\% Confidence Interval } \\
\cline { 5 - 6 } & & & & Lower & Upper \\
\hline F0-F1 & F2 & $-15.889^{*}$ & 0.002 & -26.74 & -5.04 \\
& F3 & $-18.270^{*}$ & 0.027 & -34.97 & -1.57 \\
F2 & F4 & $-46.181^{*}$ & $<.001$ & -70.62 & -21.74 \\
& F0-F1 & $15.889^{*}$ & 0.002 & 5.04 & 26.74 \\
& F3 & -2.381 & 0.980 & -18.82 & 14.06 \\
F3 & F4 & $-30.292^{*}$ & 0.009 & -54.55 & -6.04 \\
& F0-F1 & $18.270^{*}$ & 0.027 & 1.57 & 34.97 \\
& F2 & 2.381 & 0.980 & -14.06 & 18.82 \\
F4 & F4 & $-27.911^{*}$ & 0.040 & -54.94 & -.88 \\
& F0-F1 & $46.181^{*}$ & $<0.001$ & 21.74 & 70.62 \\
& F2 & $30.292^{*}$ & 0.009 & 6.04 & 54.55 \\
& F3 & $27.911^{*}$ & 0.040 & 0.88 & 54.94 \\
\hline
\end{tabular}


Table-III: Model summary of regression analysis.

\begin{tabular}{lcccc}
\hline \multicolumn{5}{c}{ Model Summary } \\
\hline Model & $R$ & $R$ & Adjusted & Std. Error of \\
& & Square & $R$ Square & the Estimate \\
\hline $10.563^{\text {a }}$ & 0.317 & 0.306 & 2.72986 \\
\hline
\end{tabular}

a. Predictors: (Constant), Serum ferritin,

Duration of Hep C.

b. Dependent Variable: TE Value (kPa).

of $\mathrm{HCV}$ and serum ferritin are significant contributors in fibrogenesis in $\mathrm{HCV}$ infection. The correlation was statistically significant our study. Documentation of ferritin as risk for fibrosis is important finding of our study with implications in patients which are at high risk to develop increased ferritin, such as patients that require repeated transfusions..$^{9,16}$

Increase in fibrosis score/stage lead to many complications of cirrhosis like portal hypertension, ascites and related further complications. It is documented that $\mathrm{CHC}$ is a major cause of cirrhosis and hepatocellular carcinoma (HCC) around the world. ${ }^{17,18}$ In the current century, which focused more on antiviral and anti-fibrotic treatments, the demand of research and proper clinical assessment for methods of noninvasive surveillance for liver fibrosis has been significantly increased all over the world. ${ }^{19}$ These methods are essentials for the estimation of the advancement and deterioration of liver fibrosis.

Beveno VI consensus defined "compensated advanced chronic liver disease (cACLD) in order to better define the spectrum of advanced fibrosis and cirrhosis in asymptomatic patients, patients with TE scores between $10-15 \mathrm{kPa}$ were labelled as suggestive while those with $>15 \mathrm{kPa}$ were labelled as highly suggestive of cACLD". ${ }^{11,20}$ Thus TE is an important investigation for better management of CHC. Fibrogenesis is the composite forceful interplay in different types of hepatic cell and intermediaries for preservation. Limitation of Fibroscan is that it could give falsely higher values in patients with acute liver injury and those with significant ALT elevations. ${ }^{21}$ Apart from Fibroscan, magnetic resonance elastography is also emerging as important noninvasive modality for assessment of liver fibrosis. Role of Ferritin is emerging as prognostic marker in cirrhosis, patients with high ferritin have been reported to have poor outcome related to hepatic insufficiency. ${ }^{22}$ Some studies have even shown that ferritin also predicts early mortality in decompensated cirrhosis. ${ }^{23}$ In study by Ricchi $P$ et al increase in ferritin levels were shown to be responsible for raised ALT and TE scores, thus down regulation of ferritin in the early stage of fibrosis should be helpful in decreasing the inflammatory effect of ferritin. ${ }^{24}$ Our study also demonstrated that ferritin has a cause/ effect relationship with TE scores in patients of $\mathrm{CHC}$. Thus it should be checked in $\mathrm{CHC}$ patients specially with cACLD.

Limitation of the Study: Our study has limitation of single center study, but we exceeded the calculated sample size to have significant effect.

\section{CONCLUSION}

There is significant correlation with cause effect relationship of ferritin with TE scores and stages proven on regression analysis. Serum ferritin should be checked in all patients of $\mathrm{CHC}$. Duration of $\mathrm{HCV}$ infection is another important factor related to TE scores.

Conflict Statement: None of the authors have any conflict of interest regarding this study.

\section{REFERENCES}

1. Lange CM, Kutalik Z, Morikawa K, Bibert S, Cerny A, Dollenmaier $G$, et al. Serum ferritin levels are associated with a distinct phenotype of chronic hepatitis C poorly responding to pegylated interferon-alpha and ribavirin therapy. Hepatol. 2012;55(4):1038-1047. doi: 10.1002/ hep.24787.

2. European Association for Study of Liver. EASL Clinical Practice Guidelines: management of hepatitis C virus infection. J Hepatol. 2014;60(2):392-420. doi: 10.1016/j. jhep.2013.11.003.

Table-IV: Details of coefficients of regression analysis with significance.

\begin{tabular}{|c|c|c|c|c|c|}
\hline \multicolumn{6}{|c|}{ Coefficients $^{\mathrm{a}}$} \\
\hline \multirow[t]{2}{*}{ Model } & \multicolumn{2}{|c|}{ Unstandardized Coefficients } & \multirow{2}{*}{$\frac{\text { Standardized Coefficients }}{\text { Beta }}$} & \multirow[t]{2}{*}{$t$} & \multirow[t]{2}{*}{ p value } \\
\hline & $B$ & Std. Error & & & \\
\hline 1 (Constant) & 3.895 & 0.952 & & 4.091 & $<0.001$ \\
\hline Duration of Hep C & 0.619 & 0.213 & 0.226 & 2.904 & 0.004 \\
\hline Serum ferritin & 0.044 & 0.007 & 0.477 & 6.145 & $<0.001$ \\
\hline
\end{tabular}

a. Dependent Variable: TE Value $(\mathrm{kPa})$. 
3. Sievert W, Altraif I, Razavi HA, Abdo A, Ahmed EA, Alomair A, et al. A systematic review of hepatitis $C$ virus epidemiology in Asia, Australia and Egypt. Liver Int 2011;31Suppl2:61-80. doi: 10.1111/j.1478-3231.2011.02540.x.

4. Vagu C, Sultana C, Ruta S. Serum iron markers in patients with chronic hepatitis C infection. Hepat Mon. 2013;13(10):e13136. doi: 10.5812/hepatmon.13136.

5. Canavan C, Eisenburg J, Meng L, Corey K, Hur C. Ultrasound elastography for fibrosis surveillance is cost effective in patients with chronic hepatitis $C$ virus in the UK. Dig Dis Sci. 2013;58(9):2691-2704. doi: 10.1007/s10620-0132705-y.

6. Nelson JE, Wilson L, Brunt EM, Yeh MM, Kleiner DE, UnalpArida A, et al. Relationship between the pattern of hepatic iron deposition and histological severity in nonalcoholic fatty liver disease. Hepatol. 2011;53(2):448-457. doi: 10.1002/ hep.24038.

7. Ruddell RG, Hoang-Le D, Barwood JM, Rutherford PS, Piva TJ, Watters DJ, et al. Ferritin functions as a proinflammatory cytokine via iron-independent protein kinase $\mathrm{C}$ zeta/ nuclear factor kappaB-regulated signaling in rat hepatic stellate cells. Hepatol. 2009;49(3):887-900. doi: 10.1002/ hep.22716.

8. Paparo F, Cevasco L, Zefiro D, Biscaldi E, Bacigalupo L, Balocco M, et al. Diagnostic value of real-time elastography in the assessment of hepatic fibrosis in patients with liver iron overload. Eur J Radiol. 2013;82(12):e755-e761. doi: 10.1016/j.ejrad.2013.08.038.

9. Ricchi P, Meloni A, Spasiano A, Costantini S, Pepe A, Cinque $\mathrm{P}$, et al. The impact of liver steatosis on the ability of serum ferritin levels to be predictive of liver iron concentration in non-transfusion-dependent thalassaemia patients. Br J Haematol. 2018;180(5):721-726. doi: 10.1111/bjh.15083.

10. Saroli Palumbo C, Restellini S, Chao CY, Aruljothy A, Lemieux C, Wild G, et al. Screening for Nonalcoholic Fatty Liver Disease in Inflammatory Bowel Diseases: A Cohort Study Using Transient Elastography. Inflamm Bowel Dis. 2019;25(1):124-133. doi: 10.1093/ibd/izy200.

11. Paternostro R, Reiberger T, Bucsics T. Elastography-based screening for esophageal varices in patients with advanced chronic liver disease. World J Gastroenterol. 2019;25(3):308229. doi: $10.3748 /$ wjg.v25.i3.308.

12. Demir M, Deyneli O, Yilmaz Y. Screening for hepatic fibrosis and steatosis in Turkish patients with type 2 diabetes mellitus: A transient elastography study. Turk J Gastroenterol. 2019;30(3):266-270. doi: 10.5152/ tjg.2018.18559.

13. Zeng J, Zhang X, Sun $C$, Pan $Q$, Lu WY, Chen $Q$, et al. Feasibility study and reference values of FibroScan 502 with $\mathrm{M}$ probe in healthy preschool children aged 5 years. BMC Pediatr. 2019;19(1):129. doi:10.1186/s12887-019-1487-6.

14. Xu Y, Liu Y, Cao Z, Wang L, Li Z, Sheng Z, et al. Comparison of FibroTouch and FibroScan for staging fibrosis in chronic liver disease: Single-center prospective study. Dig Liver Dis. 2019. doi:10.1016/j.dld.2019.02.009.

15. Salavrakos M, Piessevaux H, Komuta M, Lanthier N, Starkel P. Fibroscan Reliably Rules Out Advanced Liver Fibrosis and Significant Portal Hypertension in Alcoholic Patients. J Clin Gastroenterol. 2018. doi: 10.1097/MCG.0000000000001119.
16. Krittayaphong R, Viprakasit V, Saiviroonporn $P$, Wangworatrakul W, Wood JC. Serum ferritin in the diagnosis of cardiac and liver iron overload in thalassaemia patients real-world practice: a multicentre study. $\mathrm{Br} \mathrm{J}$ Haematol. 2018;182(2):301-305. doi: 10.1111/bjh.14776.

17. Emamaullee JA, Bral M, Meeberg G, Montano-Loza AJ, Bain VG, Burak KW, et al. HCV Eradication with DirectActing Antivirals Does Not Impact HCC Progression on the Waiting List or HCC Recurrence after Liver Transplantation. Can J Gastroenterol Hepatol. 2019;2019(2509059. doi: 10.1155/2019/2509059.

18. Nishibatake Kinoshita M, Minami T, Tateishi R, Wake T, Nakagomi R, Fujiwara N, et al. Impact of direct-acting antivirals on early recurrence of HCV-related HCC: Comparison with interferon-based therapy. J Hepatol. 2019;70(1):78-86. doi: 10.1016/j.jhep.2018.09.029.

19. Allinovi M, De Chiara L, Angelotti ML, Becherucci F, Romagnani P. Anti-fibrotic treatments: A review of clinical evidence. Matrix Biol. 2018;68-69:333-354. doi: 10.1016/j. matbio.2018.02.017.

20. de Franchis R, Baveno VIF. Expanding consensus in portal hypertension: Report of the Baveno VI Consensus Workshop: Stratifying risk and individualizing care for portal hypertension. J Hepatol. 2015;63(3):743-752. doi: 10.1016/j.jhep.2015.05.022.

21. Fallatah HI, Akbar HO, Fallatah AM. Fibroscan Compared to FIB-4, APRI, and AST/ALT Ratio for Assessment of Liver Fibrosis in Saudi Patients With Nonalcoholic Fatty Liver Disease. Hepat Mon. 2016;16(7):e38346. doi: 10.5812/ hepatmon.38346.

22. Oikonomou T, Goulis I, Soulaidopoulos S, Karasmani A, Doumtsis $\mathrm{P}$, Tsioni $\mathrm{K}$, et al. High serum ferritin is associated with worse outcome of patients with decompensated cirrhosis. Ann Gastroenterol. 2017;30(2):217-224. doi: 10.20524/aog.2016.0112.

23. Maiwall R, Kumar S, Chaudhary AK, Maras J, Wani Z, Kumar C, et al. Serum ferritin predicts early mortality in patients with decompensated cirrhosis. J Hepatol. 2014;61(1):43-50. doi: 10.1016/j.jhep.2014.03.027.

24. Afify SM, Tabll A, Nawara HM, El Kassas M, Elfert A, Seno $\mathrm{M}$, et al. Five Fibrosis Biomarkers Together with Serum Ferritin Level to Diagnose Liver Fibrosis and Cirrhosis. Clin Lab. 2018;64(10):1685-1693. doi: 10.7754/Clin. Lab.2018.180502.

\section{Authors' Contribution:}

SL: Conducted study, prepared the manuscript.

QA: Revised and edited manuscript, did data collection.

BFZ: Conceived study, did statistical analysis, gave final approval of manuscript and is responsible for integrity of research. 